\title{
ANALISIS URANIUM DAN THORIUM DALAM SEDIMEN LAUT DAN SUNGAI DI SEKITAR CALON TAPAK PLTN LEMAHABANG
}

\author{
Rosidi, Sukirno \\ P3TM BATAN Yogyakarta
}

\begin{abstract}
ABSTRAK
ANALISIS URANIUM DAN THORIUM DALAM SEDIMEN LAUT DAN SUNGAI DI SEKITAR CALON TAPAK PLTN LEMAHABANG. Penentuan uranium dan thorium telah dilakukan dengan metoda analisis aktivasi neutron (AAN) dalam cuplikan sedimen laut dan sungai. Cuplikan diiradiasi

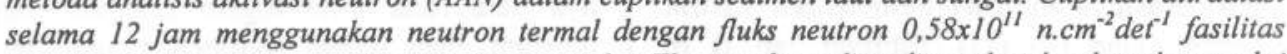
Lazy Susan di reaktor riset Kartini. Uranium dan Thorium kemudian ditentukan berdasarkan reaksi ${ }^{238} \mathrm{U}(\mathrm{n}, \gamma)^{239} \mathrm{~Np}$ dan ${ }^{232} \mathrm{Th}(\mathrm{n}, \gamma){ }^{233} \mathrm{~Pa}$. Uranium diidentifikasi melalui tenaga puncak $228,2 \mathrm{keV}$ dari ${ }^{239} \mathrm{~Np}$ dan Th melalui tenaga puncak 312 dan $300 \mathrm{keV}$ dari ${ }^{233} \mathrm{~Pa}$. Presisi dan akurasi diukur menggunakan cuplikan uji kualitas sedimen sungai SRM-1645 dan pasir monasit NBL 110-A. Metoda ini memberikan harga presisi (9-17) \% dan akurasi relatif (6-12) \% untuk kandungan thorium $(1,162-10,4) \mathrm{mg} / \mathrm{kg}$ dan kandungan uranium $(0,414-1,24) \mathrm{mg} / \mathrm{kg}$. Hasil konsentrasi $U$ dan $\mathrm{Th}$ dalam sedimen sungai dan laut masing masing $(0,224-2,703) \mathrm{mg} / \mathrm{kg}$ dan $(0,694-3,212) \mathrm{mg} / \mathrm{kg}$.
\end{abstract}

\section{ABSTRACK}

ANALYSIS OF URANIUM AND THORIUM IN SEDIMENT OF THE CANDIDATE SITE FOR NUCLEAR POWER PLANT IN LEMAHABANG REGION. The determination of uranium $(U)$ and thorium (Th) has been done using neutron activation analysis (NAA) in sea and river sediment samples. Samples were irradiated for 12 hours using thermal neutron with neutron flux of $0.58 \times 10^{\prime \prime}$ $n . \mathrm{cm}^{-2} \mathrm{sec}^{-1}$ at Lazy Susan facility in the research reactor of Kartini. Uranium and Thorium was determined as ${ }^{238} \mathrm{U}(n, \gamma){ }^{239} \mathrm{~Np}$ and ${ }^{232} \mathrm{Th}(n, \gamma){ }^{233} \mathrm{~Pa}$. Uranium was identified from peak energy 228.2 $\mathrm{keV}$ of ${ }^{239} \mathrm{~Np}$ and Th from the peak energy 312 and $300 \mathrm{keV}$ of ${ }^{233} \mathrm{~Pa}$. The precision and accuracy of the measurement were checked using standards reference material river sediment SRM-1645 and standards reference monazite sand NBL 110-A. This method gave precision ((9-17) \% and relative accuracy (6-12) \% for thorium contents of (1.162-10.4) $\mathrm{mg} / \mathrm{kg}$ and uranium of 0.414-1.24) $\mathrm{mg} / \mathrm{kg}$. The analysis result of $U$ and the concentration river and sea sediment found were $(0.224-2.703) \mathrm{mg} / \mathrm{kg}$ and $(0.694-3.212) \mathrm{mg} / \mathrm{kg}$.

\section{PENDAHULUAN}

$\mathrm{D}$ dalam kerak bumi terdapat unsur alamiah primordial yaitu jenis radioaktif alam yang sudah terbentuk semenjak terbentuknya pianet bumi ini. Unsur-unsur radioaktif yang termasuk kedalam jenis ini adalah U-238, U-235, Th-232 bersama anak luruhnya (dikenal juga dengan deret uranium dan thorium) dan K-40. Dalam peluruhan deret uranium dan thorium akan menghasilkan berbagai macam anak luruh dengan umur paro dari orde detik sampai ribuan tahun.

Uranium alam adalah campuran ${ }^{238} \mathrm{U}$ $(\sim 99,3 \%),{ }^{235} \mathrm{U}(\sim 0,7 \%)$ dan ${ }^{234} \mathrm{U}(\sim 0,006 \%)$, semua uranium ini dalam bentuk radioaktif.
${ }^{238} \mathrm{U}$ adalah permulaan deret uranium dan ${ }^{235} \mathrm{U}$ adalah awal deret actinium. Isotop uranium alam mempunyai waktu paro sangat panjang $\left(4,5 \times 10^{9}\right.$ tahun untuk $\mathrm{U}^{238}$, $7,1 \times 10^{8}$ tahun untuk ${ }^{235} \mathrm{U}$ dan $2,5 \times 10^{5}$ tahun untuk ${ }^{234} U^{(1)}$.

Thorium-232 yang mempunyai waktu paro $1,39 \times 10^{10}$ tahun adalah unsur awal dari deret peluruhan yang berakhir pada $\mathrm{Pb}-208$. Deret ini analog dengan U-238 tetapi umur paronya lebih pendek kecuali Ra-228 (6,5 tahun) dan Th-228 (1,94 tahun). Unsur thorium adalah bahan metal yang banyak digunakan baik dalam bidang nuklir maupun dalam bidang non nuklir. Dalam industri non nuklir dapat ditemukan 
dalam bentuk keramik, gelas optik, lampu kaos, elektroda tungsten dan berbagai macam logam alloy ${ }^{(1)}$.

Perkembangan industri di Indonesia khususnya di daerah pantai utara pulau Jawa yaitu daerah Semarang dan Gresik sudah semakin pesat. Rencana pemerintah yang akan direalisasi dalam waktu dekat beroperasinya industri Pembangkit Listrik Tenaga Uap (PLTU) Tanjung Jati B di Tubanan pada tahun 2005 dan rencana lokasi pembangunan Pusat Listrik Tenaga Nuklir (PLTN) telah dilakukan studi tapak dan studi lingkungan pada tahun 1991 1996 oleh konsultan NEWJEC ${ }^{(2)}$ dari Jepang. Dengan perkembangan industri tersebut tidak menutup kemungkinan terjadinya polusi terhadap lingkungan khususnya polusi zat radioaktif dan nonradioaktif. Maka perlu sedini mungkin diamati kualitas lingkungan pada waktu sekarang dan akan datang, terutama analisis atau pemantauan uranium dan thorium alam di sekitar daerah tersebut.

Analisis aktivasi neutron (AAN) adalah suatu metoda analisis unsur-unsur dalam suatu bahan cuplikan yang pengukurannya berdasarkan reaksi karakteristik dari radionuklida buatan dari unsurunsur stabil. Prinsip dasar teknik AAN ini adalah apabila suatu bahan cuplikan yang terdiri dari berbagai unsur terjadi reaksi penangkapan neutron oleh inti unsur-unsur tersebut. Bahan cuplikan diiradiasi dalam reaktor nuklir menggunakan neutron termal sehingga unsur-unsur yang terdapat dalam bahan cuplikan akan menjadi aktif dan mengeluarkan sinar gamma ${ }^{(3,4)}$. Pembuatan aktivasi radiasi dipakai sebagai teknik untuk identifikasi kualitatif dan analisis kuantitatif.

Menurut Tojo ${ }^{(3)}$ dan Grimanis ${ }^{(5)}$ salah satu cara analisis unsur dalam suatu cuplikan baik kualitatif maupun kuantitatif adalah menggunakan teknik aktivasi neutron yang saat ini sudah berkembang pesat dan telah diterapkan dalam berbagai jenis penentuan unsur. Sukirno $\mathrm{dkk}^{(6)}$ telah melakukan analisis multiunsur dalam sedimen dimana dalam sedimen tersebut terdeteksi 26 unsur yang digolongkan dalam unsur kelumit, minor dan mayor. Selain itu teknik ini bersifat instrumental atau tanpa pemisahan radiokimia sehingga tidak memerlukan terlalu banyak tenaga.

Tujuan penelitian ini adalah tersusunnya data rona awal logam uranium dan thorium alam dalam sedimen sungai dan laut di daerah calon tapak PLTN Ujung Lemahabang, yang mengakomodasikan data lingkungan terkini dalam rangka memperoleh izin tapak dan AMDAL PLTN.

\section{TATA KERJA}

\section{Alat}

Reaktor Nuklir Kartini, seperangkat sepektrometer gamma dengan detektor $\mathrm{Ge}(\mathrm{Li})$, timbangan Analitik Ohaus-GT 410, ayakan Karl Colb 100 mesh, agat porselin, Vial polietilen, cawan, dan alat-alat gelas.

Bahan

Bahan kimia $\mathrm{Th}\left(\mathrm{NO}_{3}\right)_{4} .5 \mathrm{H}_{2} \mathrm{O}$ (Merck), $\mathrm{UO}_{2}\left(\mathrm{NO}_{3}\right)_{2} \cdot 6 \mathrm{H}_{2} \mathrm{O}$ (Merck), NBL 106 Campuran $\mathrm{U}$ dan $\mathrm{Th}$ dalam pasir monasit dari New Brunswich Laboratory USA, River sediment NBS Kode SRM 1645 dan pasir monasit NBL 110-A, cellulose powder, Sedimen laut dan sungai di sekitar Lemahabang, tempat sedimen basah dan kering yang berlabel.

\section{Cara kerja}

Sedimen sungai Balong, Suru, Kancilan, Gelis dan sedimen laut diambil di kawasan rencana lokasi pembangunan PLTN. Sedimen dikeringkan dan dihilangkan dari kotoran kemudian dihaluskan lolos 100 mesh lolos dan dihomogenkan dan ditempatkan dalam wadah yang bebas kontaminasi. Sedimen dalam wadah tersebut telah siap untuk dianalisis kandungan uranium dan thoriumnya dengan metoda analisis aktivasi neutron. 
Dibuat cuplikan standar sekunder thorium dari $\mathrm{Th}\left(\mathrm{NO}_{3}\right)_{4} .5 \mathrm{H}_{2} \mathrm{O}$ dan uranium dari $\mathrm{UO}_{2}\left(\mathrm{NO}_{3}\right)_{2}, 6 \mathrm{H}_{2} \mathrm{O}$ yang diencerkan dalam selulosa dengan konsentrasi 1 - 25 $\mathrm{mg} / \mathrm{kg}$. Cuplikan ditimbang masing-masing seberat $0,1 \mathrm{~g}$ dalam vial. Cuplikan sedimen, standar sekunder dan primer dimasukkan dalam kelongsong iradiasi.

Iradiasi cuplikan dilakukan dalam fasilitas Lazy Susan selama 12 jam dengan fluks neutron $0,58 \times 10^{11} \mathrm{n} \cdot \mathrm{cm}^{-2} \operatorname{det}^{-1}$. Setelah iradiasi dihentikan kemudian didinginkan selama 6 hari dan kemudian dilakukan pencacahan radionuklida $\mathrm{Pa}-233$ dengan puncak tenaga 300 dan $312 \mathrm{keV}$ untuk mengetahui adanya thorium dan Np-239 dengan tenaga puncak $228,2 \mathrm{keV}$ untuk uranium. Pencacahan dilakukan dengan menggunakan spektrometri gamma dengan detektor $\mathrm{Ge}(\mathrm{Li})$ selama 1.000 detik.

Persamaan yang digunakan untuk menghitung aktivitas dan kadar $\mathrm{U}$ dan $\mathrm{Th}$ dalam sedimen adalah persamaan (1), untuk mengetahui aktivitas cuplikan menuju waktu pada saat iradiasi dihentikan (No). Sedangkan persamaan (2) untuk mengetahui kadar $\mathrm{U}$ dan Th dalam sedimen dengan metoda komparatif.

$$
\begin{aligned}
& \text { No }=N t \cdot e^{0,693 t / T} \\
& W_{\text {cuplikan }}=\frac{\mathrm{No}_{\text {cuplikan }}}{\mathrm{No}_{\text {stan dar }}} \cdot \mathrm{W}_{\text {stan dar }}
\end{aligned}
$$

dengan

$\mathrm{W}=$ kadar unsur yang diperhatikan $\mathrm{mg} / \mathrm{kg}$

$\mathrm{Nt}=$ Laju cacah pada saat pencacahan (sps)

No $=$ Laju cacah pada saat iradiasi dihentikan (cps)

$\mathrm{T}=$ waktu paro (detik)

$\mathrm{t}=$ waktu tunda (detik)

Untuk menghitung presisi persamaan (3) dan akurasi persamaan (4)

$$
\begin{aligned}
& \text { Presisi }=\frac{\mathrm{S}_{\mathrm{C}}}{\mathrm{K}_{\mathrm{R}}} \times 100 \% \\
& \text { Akurasi }=\left|\frac{\mathrm{K}_{\mathrm{S}}-\mathrm{K}_{\mathrm{T}}}{\mathrm{K}_{\mathrm{S}}}\right|
\end{aligned}
$$

dengan

$\mathrm{S}_{\mathrm{B}}, \mathrm{S}_{\mathrm{C}}=$ Simpangan baku latar \& cuplikan
$\mathrm{K}_{\mathrm{R}} \quad=$ Kadar rerata cuplikan $(\mathrm{mg} / \mathrm{kg})$

$\mathrm{K}_{\mathrm{S}} \quad=$ Kadar unsur sertifikat $(\mathrm{mg} / \mathrm{kg})$

$\mathrm{K}_{\mathrm{T}} \quad=$ Kadar unsur terukur $(\mathrm{mg} / \mathrm{kg})$

\section{HASIL DAN PEMBAHASAN}

\section{Penentuan secara kualitatif}

Penentuan unsur secara kualitatif dilakukan dengan menentukan tenaga dari puncak-puncak spektrum kemudian mencocokkan dengan tabel isotop. Pada Tabel 1 merupakan hasil identifikasi radionuklida secara kualitatif untuk mengetahui uranium dan thorium dengan metoda analisis aktivasi neutron (AAN) dilakukan berdasarkan reaksi aktivasi neutron, seperti di bawah ini:

$\mathrm{U}^{238}(\mathrm{n}, \gamma) \mathrm{U}^{239} \stackrel{\beta, \gamma, 23,5 \mathrm{~m}}{\longrightarrow} \mathrm{Np}^{239} \stackrel{\beta, \gamma 2,33 \mathrm{~h}}{\longrightarrow} \mathrm{Pu}^{239}$ $\mathrm{Th}^{232}(\mathrm{n}, \gamma) \mathrm{Th}^{233} \stackrel{\beta, \gamma 22,1 \mathrm{~m}}{\longrightarrow} \mathrm{Pa}^{233} \stackrel{\beta, \gamma 27 \mathrm{~h}}{\longrightarrow} \mathrm{U}^{233}$ Pada reaksi aktivasi tersebut $\mathrm{U}^{238}$ dan $\mathrm{Th}^{232}$ ditentukan dari radionuklida $\mathrm{Np}^{239}$ dan $\mathrm{Pa}^{233}$, kedua radionuklida ini merupakan anak luruh dari $\mathrm{U}^{239}$ dan $\mathrm{Th}^{233}$. Radionuklida $\mathrm{Np}^{239}$ memancarkan sinar gamma pada tenaga $228,2 \mathrm{keV}$ dengan probabilitas $10,72 \%$ dan tenaga $277,6 \mathrm{keV}$ dengan probabilitas $14,10 \%$ dengan umur paro 2,33 hari sedangkan dan $\mathrm{Pa}^{233}$ pada tenaga $300,1 \mathrm{keV}$ dengan probabilitas $5,80 \%$ dan $311,8 \mathrm{keV}$ dengan probabilitas $33,70 \%$ dengan umur paro 27,4 hari. Radionuklida $\mathrm{Np}^{239}$ dan $\mathrm{Pa}^{233}$, mempunyai lebih dari satu tenaga atau mempunyai multi tenaga gamma ${ }^{(7)}$.

Tabel 1. Proses $(\mathrm{n}, \gamma)$ dengan memperhatikan hasil nuklida hasil AAN yang diperhatikan

\begin{tabular}{|l|l|l|l|}
\hline $\begin{array}{c}\text { Radio } \\
\text { nuklida }\end{array}$ & Tenaga (keV) & Probabilitas ,\% & $\begin{array}{c}\text { Nuklida } \\
\text { hasil }\end{array}$ \\
\hline U-238 & 228,$2 ; 277,6$ & 10,$72 ; 14,10$ & Np-239 \\
\hline Th-232 & 300,$1 ; 311,8$ & 5,$80 ; 33,70$ & Pa-233 \\
\hline
\end{tabular}

\section{Penentuan secara kuantitatif}

Setelah dipilih radionuklida $\mathrm{Np}^{239}$ dan $\mathrm{Pa}^{233}$ yang mempunyai probabilitas terbesar secara kualitatif, maka selanjutnya adalah penentuan secara kuantitatif. Analisis 
kuantitatif ini dilakukan dengan metoda komparatif radionuklida dalam cuplikan dengan radionuklida yang ada dalam standar sekunder, dengan menggunakan persamaan (2).

Hasil kuantitatif logam berat uranium dan thorium alam yang terdapat dalam sedimen laut maupun sungai disajikan pada Tabel 2, dan dapat dilihat pada lampiran, Gambar 1, histrogram kadar $U$ dan Th terukur berbagai tempat sampling. Pada tabel tersebut terlihat bahwa kadar thorium pada umumnya lebih besar dari pada uranium, di sedimen laut maupun sedimen sungai. Akan tetapi mempunyai kadar yang berbeda walaupun tidak mencolok, uranium dan thorium yang terdeteksi merupakan uranium dan thorium alam yang sejak terbentuknya tanah tersebut sudah ada. Kadar terendah untuk uranium terdapat pada sungai Balong 0,224 $\pm 0,056 \mathrm{mg} / \mathrm{kg}$, sedangkan kadar yang tertinggi terdapat di sungai Balong Muara 2,703 $\pm 0,324 \mathrm{mg} / \mathrm{kg}$. Untuk thorium kadar terendah terdapat pada sungai Kancilan dengan konsentrasi $0,694 \pm 0,27 \mathrm{mg} / \mathrm{kg}$ dan kadar tertinggi terdapat di sungai Balong Muara dengan $3,212 \pm 0,588 \mathrm{mg} / \mathrm{kg}$.

\section{Pengujian mutu hasil analisis dengan metoda AAN}

Presisi (keseksamaan) dan akurasi (ketelitian) sangat perlu dilakukan untuk menguji hasil analisis dari suatu perhitungan pencacahan cuplikan yang telah diiradiasi dengan menggunakan alat spektrometer gamma. Selain itu semua masalah yang masih timbul tersebut dapat dikontrol dengan harga presisi dan harga akurasinya.

Tabel 2. Data hasil pengukuran kadar uranium dan thorium dalam sedimen

\begin{tabular}{|l|c|c|}
\hline \multirow{2}{*}{ Nama Sedimen } & \multicolumn{2}{|c|}{ Kadar $(\mathrm{mg} / \mathrm{kg})$} \\
\cline { 2 - 3 } & Uranium & Thorium \\
\hline Laut Lemahabang & $0,681 \pm 0,144$ & $0,754 \pm 0,214$ \\
Sungai Balong & $0,224 \pm 0,056$ & $1,309 \pm 0,124$ \\
Balong Muara & $2,703 \pm 0,324$ & $3,212 \pm 0,588$ \\
Sungai Suru & $1,076 \pm 5,088$ & $1,202 \pm 1,590$ \\
Sungai Kancilan & $0,567 \pm 0,019$ & $0,694 \pm 0,272$ \\
\hline
\end{tabular}

Pada dasarnya akurasi hasil analisis diuji dengan memperbandingkan terhadap cuplikan acuan standar (standard referrence material, SRM). Dari pengukuran standar sekunder dimasukkan hasil aktivasi standar primer yang telah ditentukan kadarnya. Dengan mengaplikasikan persamaan (2) pada data yang diperoleh untuk standar primer NBL 110A dan SRM 1645 dapat dihasilkan seperti dalam Tabel 3.

Akurasi yang terukur pada Tabel 3, misalnya dalam sertifikat dari sedimen SRM 1645 mempunyai kadar uranium 1,11 $\mathrm{mg} / \mathrm{kg}$ setelah dilakukan aktivasi neutron kadar yang terukur mempunyai kadar 1,240 $\pm 0,131 \mathrm{mg} / \mathrm{kg}$, dan setelah dimasukkan persamaan (4) didapatkan harga akurasi $9,00 \%$, pengukuran ini dilakukan pengulangan 5 kali. Pada Tabel 3, untuk kadar uranium $(0,414-1,11)$ pada standar primer mempunyai akurasi sebesar $(9,00-11.98)$ $\%$ dan thorium dari kadar $(1,62-10,40)$ $\mathrm{mg} / \mathrm{kg}$ mempunyai akurasi sebesar $(6,46$ 9,29) \%. Hal ini menunjukkan bahwa metoda analisis untuk menentukan uranium maupun thorium secara kuantitatif mempunyai ketelitian yang relatif baik. Sedang yang diperbolehkan untuk analisis suatu unsur dengan metoda AAN mempunyai akurasi maksimal 15\%.

Presisi merupakan keseksamaan dari pengukuran unsur $U$ dan $T h$ setelah perlakuan aktivasi neutron termal dengan menggunakan spektrometer gamma dengan detektor yang digunakan. Hasil presisi disajikan pada Tabel 3, dari perhitungan dengan menggunakan persamaan (3), hasilnya sekitar $10 \%$ sampai dengan $15 \%$. Hal ini menunjukkan bahwa metoda yang digunakan untuk menentukan $\mathrm{U}$ dan $\mathrm{Th}$ pada cuplikan sertifikat yang telah diketahui kadarnya tidak jauh berbeda dengan pengukuran dengan menggunakan standar sekunder.

Untuk akurasi dapat dibuat histrogram, ini dapat dilihat pada lampiran Gambar 2, histrogram akurasi (\%) berbagai kadar untuk $\mathrm{U}$ dan $\mathrm{Th}$ dengan kadar yang 
uranium dari $0,414 \mathrm{ppm}$ sampai dengan 1,11 ppm dan thorium dari 1,62 ppm sampai dengan $10,40 \mathrm{ppm}$.

Tabel 3. Data hasil pengukuran kadar terukur dalam sertifikat dari sedimen SRM 1645 dan pasir monasit NBL 110-A untuk menentukan presisi dan akurasi

\begin{tabular}{|l|l|l|c|c|c|}
\hline \multirow{2}{*}{$\begin{array}{l}\text { Kode } \\
\text { standar }\end{array}$} & Un & \multicolumn{2}{|c|}{ Kadar mg/kg } & Presisi, & Akurasi, \\
\cline { 3 - 4 } & sur & Sertifikat & Terukur & $\%$ & $\%$ \\
\hline NBL & U & 0,414 & $0,535 \pm 0,067$ & 12,52 & 11,98 \\
$110 A$ & TH & 10,40 & $11,07 \pm 0,803$ & 7,253 & 6,46 \\
\hline SRM & U & 1,11 & $1,240 \pm 0,131$ & 10,56 & 9,00 \\
1645 & Th & 1,62 & $1,275 \pm 0,207$ & 16,23 & 9,29 \\
\hline
\end{tabular}

\section{KESIMPULAN}

Beberapa hal yang dapat disimpulkan dari hasil pembahasan dan penting untuk diingat adalah sebagai berikut:

1. Dengan menggunakan metoda AAN dapat ditentukan unsur uranium melalui anak luruh $\mathrm{U}^{239}$ yaitu $\mathrm{Np}^{239}$ dan thorium melalui anak luruh $\mathrm{Th}^{233}$ yaitu $\mathrm{Pa}^{233}$ yang memancarkan sinar gamma.

2. Analisis $U$ dan $T h$ dengan metoda $A A N$ mempunyai presisi untuk uranium 10,56 $\%$ dan akurasi relatif $9,00 \%$ untuk kadar $1,11 \mathrm{mg} / \mathrm{kg}$, sedangkan untuk thorium $9,304 \%$ dan akurasi relatif $6,460 \%$ untuk kadar $10,40 \mathrm{mg} / \mathrm{kg}$.

3. Kadar $U$ dan $T h$ dalam sedimen sungai dan sedimen laut masing masing berkisar antara $(0,224-2,703) \mathrm{mg} / \mathrm{kg}$ dan $(0,694-3,212) \mathrm{mg} / \mathrm{kg}$.

\section{DAFTAR PUSTAKA}

1. BENEDICT $\mathrm{M}$, and PIGFORD, T.H., Nuclear chemical engineering. Ed $2^{\text {nd }}$, McGraw-Hill Book Company, New York (1981).

2. NEWJEC, Laporan Environment Impact Assessment Report, Feasibility Study of the First Nuclear Power Plant at Muria Peninsula Region, central Java, Jakarta (1996).

3. TAKAO TOJO, Instrumental Neutron Activation Analysis, BATAN JAERI Training Course on Radiation Measurement and Nuclear Spectroscopy, Jakarta (1998).

4. KRUGER P., Principles of activation Analysis, Wiley-Interscience, New York, (1971).

5. GRIMANIS, A.P., "Neutron Activation Analysis In Greece", Significance and Impact of Nuclear Research In Developing Countries, IAEA, VIENNA (1987).

6. SUKIRNO, SUDARMADJI, "Aplikasi APN Untuk Menentukan Multiunsur dalam sedimen, Prosiding PPI, P3TM BATAN, Yogyakarta (1999).

7. ERDTMANN, G., Neutron activation tables, New York (1976).

8. IAEA, Measurement of Radionuclides in Food and The Environment, A Guide Book, Tech Rep Ser No 295, IAEA, Vienna (1989). 


\section{LAMPIRAN}

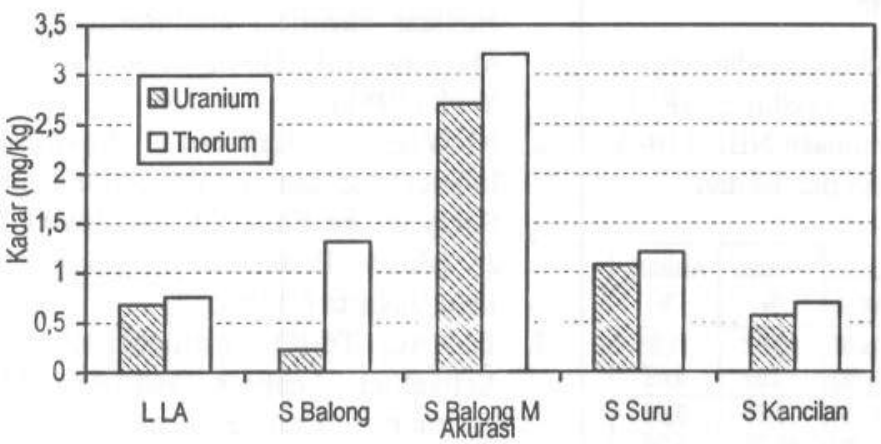

Gambar 1. Histrogram kadar U dan Th terukur berbagai tempat sampling.

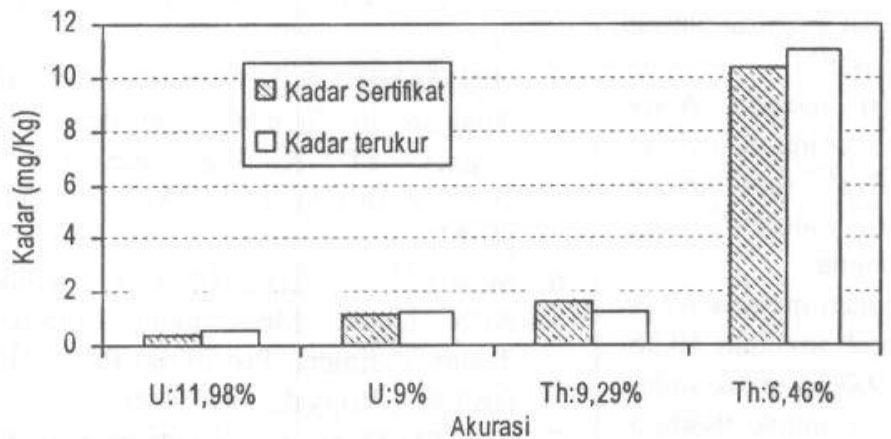

Gambar 2. Histrogram akurasi (\%) berbagai kadar untuk U dan Th. 